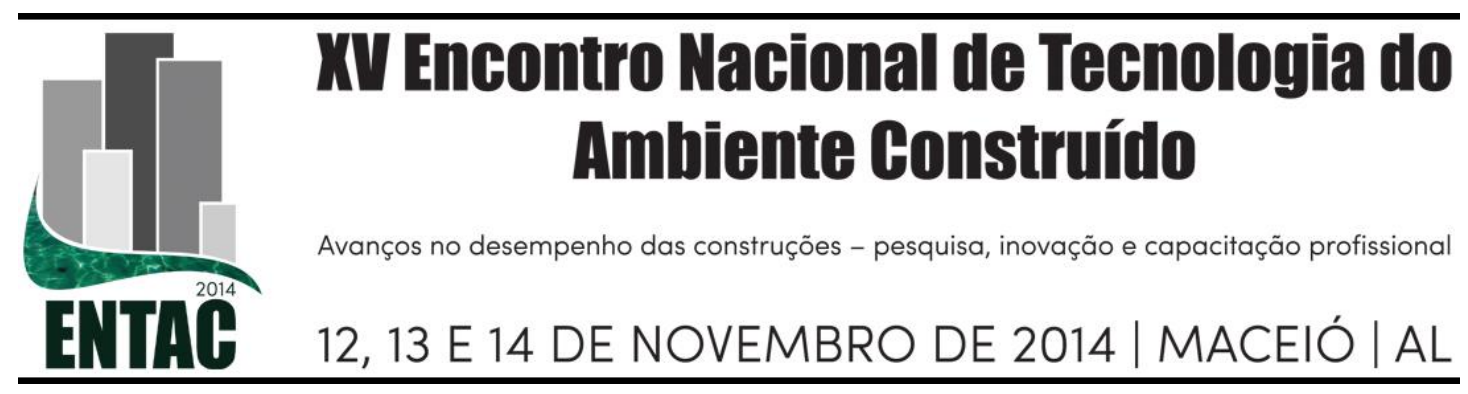

\title{
AVALIAÇÃO DO PROCESSO DE PROJETO EM EMPREENDIMENTOS IMOBILIÁRIOS
}

\author{
LEITE, Kelma Pinheiro (1); BARROS NETO, José de Paula (2) \\ (1) Universidade Federal do Ceará, e-mail: kelmapinheiro@yahoo.com.br, (2) Universidade Federal do \\ Ceará, e-mail: jpbarros@ufc.br
}

\begin{abstract}
RESUMO
Este artigo apresenta os resultados da survey sobre o processo de projeto em projetos imobiliários na cidade de Fortaleza, Brasil. O objetivo principal é descrever como os projetistas e construtores avaliam o processo de projeto imobiliário, a fim de melhorar a compreensão de suas expectativas e necessidades. Como resultado, foram identificadas oportunidades de melhoria do processo de desenvolvimento de produto imobiliário. Este estudo baseou-se no referencial teórico da literatura sobre pensamento enxuto, lean design, processo de projeto e desenvolvimento de produtos imobiliários. Os dados foram coletados através de 90 questionários preenchidos por projetistas e engenheiros de obra em incorporadoras e construtoras. As principais questões de insatisfação identificadas foram: retrabalho; planejamento deficiente do processo desenvolvimento de produto imobiliário; os prazos estipulados e compatibilização.
\end{abstract}

PALAVRAS-CHAVE: Processo de Projeto, Mercado Imobiliário, Construção Enxuta, Lean Design.

\begin{abstract}
This paper presents the results of a research about the design process in real estate projects in Fortaleza, Brazil. The main aim is to investigate how designers and construction engineers evaluate the design process, through understanding their expectations and needs by identifying opportunities to process improvement. This study was based on the theoretical framework of lean design literature, the design process and development of real estate products. The research method is a survey, and data was collected through 90 questionnaires completed by designers and building engineers in construction companies and design offices. The main issues of dissatisfaction identified by descriptive analysis from the perspective of designers and builders are, respectively: rework; planning of the design processes; the project delivery terms; project deadline; and clash detection.
\end{abstract}

Keywords: Design process, Real estate process, Lean Construction, Lean Design.

\section{INTRODUÇÃ̃O}

O mercado imobiliário confronta-se com um processo de produção complexo e singular, com diferentes agentes envolvidos que mantém uma atuação fragmentada, temporária e interesses próprios, e muitas vezes divergentes quanto às características e objetivos do empreendimento (OLIVEIRA, 2004; ROMANO, 2003; FABRÍCIO, 2002). Estes empreendimentos complexos e com multi-interessados altera profundamente a dinâmica da relação entre projeto e construção e a gestão das atividades entre os dois (ANDERSEN et al, 2005). Além disso, a equipe do projeto é composta de uma relação menos hierárquica e mais horizontal (ORIHUELA et al, 2011). Pelo envolvimento de 
várias empresas no desenvolvimento do projeto, aumenta-se a complexidade do processo de projeto e torna sua coordenação ainda mais difícil (MOURA, 2005).

A percepção da necessidade de integração entre projeto e produção na construção civil tem ganhado maior atenção (TRESCASTRO, 2005). Sob um ponto de vista contratual, a divisão do desenvolvimento do produto por fases é utilizada para tornar mais fácil a definição dos papéis e responsabilidades dos diferentes atores em um empreendimento, porém distancia projetistas da obra (ANDERSEN et al, 2005) e prejudica a comunicação e desenvolvimento do produto (JORGENSEN, 2006). Morgan e Liker (2008) chamam o Sistema Toyota de Desenvolvimento de Produtos (STDP) de processo de engenharia simultâneo, colaborativo, onde os participantes interagem com objetivo de avaliar múltiplas alternativas, através de um planejamento cuidadoso e execução com precisão.

A filosofia lean tem o foco na adição de valor sob o ponto de vista do cliente e eliminação ou redução de perdas. A partir de uma abordagem holística, é natural se aplicar o pensamento enxuto para todas as fases de um empreendimento, desde a concepção e construção até o uso e manutenção (BALLARD e KOSKELA, 1998). Entretanto, para Trescastro (2003), existe certa dificuldade na visualização de restrições por parte dos projetistas, o que pode ser um limitador para o fluxo contínuo do processo de projeto e do uso do last planner $^{1}$ em empreendimentos imobiliários.

Para Tzortzopoulos e Formoso (1999) e Koskela (2000), a aplicação de princípios da construção enxuta para o processo de projetos deve considerar três visões diferentes do projeto: (1) projeto como conversão; (2) projeto como fluxo (de informações); e (3) projeto como geração de valor (sob o ponto de vista do cliente). Para Koskela (2000), a visão de conversão é a mais investigada e melhor compreendida, enquanto as questões de fluxo e, principalmente, a geração de valor foram negligenciadas no modelo tradicional de projeto.

O objetivo principal deste trabalho é descrever como os projetistas e construtores avaliam o processo de projeto imobiliário, a fim de melhorar a compreensão de suas expectativas e necessidades. Como resultado, foram identificadas oportunidades de melhoria do processo de desenvolvimento de produto imobiliário.

\section{MÉTODO}

Para o levantamento de dados sobre o processo de projeto de empreendimentos imobiliários, foi aplicada uma survey. A pesquisa aqui proposta é considerada exploratória, por adquirir uma visão macro sobre um fenômeno, e descritiva, por ser dirigida ao seu entendimento, fornecendo subsídios para a teoria. As questões foram divididas em duas grandes seções: a primeira com informações acerca do perfil dos respondentes; e a segunda com questões sobre o processo de projeto e seu planejamento. Foi realizado um pré-teste para validação das perguntas e, após as revisões necessárias, foi formulado um questionário final.

Foram selecionados escritórios de projeto e empresas de construção civil que estão envolvidos no processo de desenvolvimento de produtos imobiliários multifamiliares verticais. Os projetistas de arquitetura foram mapeados pelo registro na associação ASBEA (Associação Brasileira dos Escritórios de Arquitetura). Devido à grande quantidade de empresas incorporadoras e construtoras no estado do Ceará, as empresas de construção foram selecionadas através do registro no Inovacon (Programa de Inovação da Indústria da Construção) e Coopercon (Cooperativa de Construção do Ceará - entidade que visa a compra conjunta de insumos para construtoras

\footnotetext{
${ }^{1}$ Ferramenta desenvolvida por Ballard e largamente utilizada na construção, através da filosofia enxuta.
} 
concorrentes). Assim, os escritórios de projeto entrevistados representam $36 \%$ dos filiados à ASBEA e as incorporadoras e construtoras $20 \%$ das empresas que são filiadas à Coopercon. Os escritórios de projeto de cálculo estrutural e instalações foram identificados a partir das obras visitadas.

Os questionários foram preenchidos por arquitetos e engenheiros, no entanto, estes foram divididos em dois grupos: construtores (com 22 questões) e projetistas (com 24 questões). Haviam questões fechadas, utilizando a escala de Likert com 07 níveis (Tabelas 2 e 3), perguntas fechadas com escolha de mais de uma opção (gráficos 1 a 6), e questões abertas.

A pesquisa teve duração de 09 meses, desde a montagem das perguntas ao seu relatório final. Os questionários foram aplicados em 13 empresas incorporadoras e construtoras e 17 escritórios de projeto, perfazendo um total de 90 . Deste total, 22 foram respondidos em obras e 65 em escritórios de projeto. Esses números referem-se àqueles que retornaram à survey, havendo uma taxa de retorno de $80 \%$. Ressalta-se que os questionários foram entregues em cada local de aplicação em formato impresso, para posterior coleta. Percebeu-se que com esta ação houve um aumento no retorno, comparando-se com outros trabalhos com mesmo método. $\mathrm{Na}$ tabela 1, podemos verificar um resumo do perfil dos respondentes.

Tabela 1: Perfil das organizações e profissionais respondentes.

\begin{tabular}{cccc}
\hline Tipo de Organização & Quantidade & Tipo de profissional & Quantidade \\
\hline Escritório de Arquitetura & 09 & Arquiteto & 29 \\
\hline Escritório de Paisagismo & 02 & Eng. Projetista & 14 \\
\hline Cálculo Estrutural & 02 & Téc. Projetista & 19 \\
\hline Instalações & 03 & Eng. Obra & 25 \\
\hline Ambientação & 02 & Design de interiores & 1 \\
\hline Incorporadora e Construtora & 13 & Agrônomo & 1 \\
\hline
\end{tabular}

Fonte: os autores.

\section{RESULTADOS}

Os escritórios de projeto possuem portes diferentes, tendo uma média de 08 colaboradores. Apenas três estavam acima dessa faixa, com: 34 (arquitetura); 23 (cálculo estrutural); e 26 (instalações). As perguntas aplicadas eram semelhantes em escritórios de projeto e obras, de forma que fosse possível uma posterior comparação das respostas entre os dois grupos. A compilação das respostas para as questões fechadas, utilizando a escala de Likert, pode ser encontrada nas tabelas 2 e 3 abaixo. 
Tabela 2: Nível de satisfação dos escritórios de projeto com o processo de projeto

\begin{tabular}{|c|c|c|c|c|c|c|c|}
\hline Grau de satisfação com: & $\begin{array}{l}\mathbf{E X} \\
(\%)\end{array}$ & $\begin{array}{l}\text { MS } \\
(\%)\end{array}$ & $\begin{array}{l}\text { SF } \\
(\%)\end{array}$ & $\begin{array}{l}\text { NT } \\
(\%)\end{array}$ & $\begin{array}{l}\text { PC } \\
(\%)\end{array}$ & $\begin{array}{l}\text { MP } \\
(\%)\end{array}$ & $\begin{array}{l}\text { ND } \\
(\%)\end{array}$ \\
\hline $\begin{array}{l}\text { Planejamento do processo de } \\
\text { projeto atual de seus clientes }\end{array}$ & 4.55 & 4.55 & 37.88 & 30.30 & 22.73 & 0.00 & 0.00 \\
\hline $\begin{array}{l}\text { Planejamento do processo de } \\
\text { projeto do escritório? }\end{array}$ & 4.35 & 14.49 & 47.83 & 10.14 & 13.04 & 10.14 & 0.00 \\
\hline $\begin{array}{l}\text { Interesse do escritório em adotar } \\
\text { novas práticas e ferramentas para o } \\
\text { planejamento e controle do } \\
\text { processo de projeto? }\end{array}$ & 13.24 & 54.41 & 20.59 & 7.35 & 1.47 & 1.47 & 1.47 \\
\hline $\begin{array}{l}\text { As soluções adotadas no projeto } \\
\text { para etapa de execução da obra? }\end{array}$ & 11.76 & 20.59 & 39.71 & 17.65 & 8.82 & 1.47 & 0.00 \\
\hline $\begin{array}{l}\text { A precisão dos desenhos e } \\
\text { informações contidas nos projetos } \\
\text { realizados pelo escritório? }\end{array}$ & 14.71 & 32.35 & 47.06 & 4.41 & 1.47 & 0.00 & 0.00 \\
\hline $\begin{array}{l}\text { A compatibilização dos projetos } \\
\text { desenvolvidos pelo escritório com } \\
\text { as outras disciplinas do projeto? }\end{array}$ & 5.88 & 20.59 & 42.65 & 11.76 & 10.29 & 7.35 & 1.47 \\
\hline $\begin{array}{l}\text { Entregas por etapas dos projetos } \\
\text { desenvolvidos pelo escritório? }\end{array}$ & 5.88 & 27.94 & 42.65 & 16.18 & 7.35 & 0.00 & 0.00 \\
\hline $\begin{array}{l}\text { O fluxo de informações entre o } \\
\text { escritório e os contratantes? }\end{array}$ & 3.03 & 13.64 & 39.39 & 24.24 & 15.15 & 4.55 & 0.00 \\
\hline $\begin{array}{l}\text { O fluxo de informações entre o } \\
\text { escritório e os demais escritórios? }\end{array}$ & 1.49 & 13.43 & 34.33 & 22.39 & 16.42 & 10.45 & 1.49 \\
\hline $\begin{array}{l}\text { Transmissão de informação durante } \\
\text { as etapas de projeto no escritório? }\end{array}$ & 4.41 & 14.71 & 42.65 & 23.53 & 11.76 & 2.94 & 0.00 \\
\hline Prazos estabelecidos pelo cliente? & 1.47 & 7.35 & 29.41 & 32.35 & 23.53 & 1.47 & 4.41 \\
\hline $\begin{array}{l}\text { O projeto não inicia sem que as } \\
\text { restrições de projeto tenham sido } \\
\text { removidas (entrada de informação). }\end{array}$ & 3.13 & 3.13 & 34.38 & 26.56 & 17.19 & 9.38 & 6.25 \\
\hline
\end{tabular}

EX: extremamente, MS: muito satisfeito, SF: satisfeito, NT: neutro, PC: pouco, MP: muito pouco. ND: nada.

Fonte: os autores.

Analisando-se os percentuais de graus de satisfação dos entrevistados dos escritórios de projeto, as questões que obtiveram os mais altos níveis de insatisfação foram quanto à remoção de restrições $(32,82 \%)$ e prazos estabelecidos pelo cliente $(29,41 \%)$. Destacamos as questões as quais foram avaliadas positivamente pelos projetistas: precisão de desenhos e informações contidos nos projetos realizados pelo escritório de 
projeto $(94,12 \%)$ e interesse do escritório de projeto em adotar novas práticas e ferramentas para planejamento e controle do processo de projeto $(88,24 \%)$.

Tabela 3: Nível de satisfação dos Construtores com o processo de projeto.

\begin{tabular}{l|l|l|l|l|l|l|l}
\hline \multicolumn{1}{c|}{ Grau de satisfação com: } & $\begin{array}{c}\text { EX } \\
(\%)\end{array}$ & $\begin{array}{c}\text { MS } \\
(\%)\end{array}$ & $\begin{array}{c}\text { SF } \\
(\%)\end{array}$ & $\begin{array}{c}\text { NT } \\
(\%)\end{array}$ & $\begin{array}{c}\text { PC } \\
(\%)\end{array}$ & $\begin{array}{c}\text { MP } \\
(\%)\end{array}$ & $\begin{array}{c}\text { ND } \\
(\%)\end{array}$ \\
\hline $\begin{array}{l}\text { O atual planejamento do processo } \\
\text { de projeto da empresa }\end{array}$ & 4.17 & 8.33 & 41.67 & 4.17 & 33.33 & 4.17 & 4.17 \\
\hline $\begin{array}{l}\text { O atual planejamento do processo } \\
\text { de projeto dos projetistas }\end{array}$ & 0.00 & 4.17 & 25.00 & 8.33 & 37.50 & 12.50 & 12.50 \\
\hline $\begin{array}{l}\text { Interesse em adotar novas práticas } \\
\text { e ferramentas de planejamento e } \\
\text { controle do processo de projeto }\end{array}$ & 17.39 & 60.87 & 21.74 & 0.00 & 0.00 & 4.35 & 0.00 \\
\hline $\begin{array}{l}\text { As soluções de projeto adotadas na } \\
\text { perspectiva da execução da obra }\end{array}$ & 0.00 & 0.00 & 45.83 & 12.50 & 25.00 & 12.50 & 4.17 \\
\hline $\begin{array}{l}\text { Precisão das informações contidas } \\
\text { nos desenhos e projetos realizados } \\
\text { pelos projetistas? }\end{array}$ & 0.00 & 0.00 & 45.83 & 12.50 & 16.67 & 16.67 & 8.33 \\
\hline $\begin{array}{l}\text { Compatibilização dos projetos } \\
\text { Entregas por etapas dos projetos } \\
\text { desenvolvidos pelos projetistas }\end{array}$ & 0.00 & 0.00 & 20.83 & 20.83 & 33.33 & 16.67 & 8.33 \\
\hline $\begin{array}{l}\text { Fluxo de informações entre os } \\
\text { escritórios de projetos e a empresa }\end{array}$ & 0.00 & 4.35 & 39.13 & 17.39 & 26.09 & 8.70 & 4.35 \\
\hline $\begin{array}{l}\text { Disponibilização de informações } \\
\text { do processo de projeto em um local } \\
\text { de fácil acesso na empresa (fluxos, } \\
\text { cronogramas, indicadores) }\end{array}$ & 0.00 & 16.67 & 37.50 & 20.83 & 16.67 & 0.00 & 8.33 \\
\hline $\begin{array}{l}\text { Interligação entre o departamento } \\
\text { de projetos/ obra para que haja } \\
\text { retroalimentação no projeto }\end{array}$ & 0.00 & 8.33 & 29.17 & 20.83 & 29.17 & 8.33 & 4.17 \\
\hline
\end{tabular}

EX: extremamente, MS: muito satisfeito, SF: satisfeito, NT: neutro, PC: pouco, MP: muito pouco. ND: nada.

Fonte: os autores.

Analisando-se os percentuais de graus de satisfação dos respondentes nas obras, as questões que obtiveram os mais altos níveis de insatisfação foram planejamento do processo de projeto dos escritórios de projeto $(62,50 \%)$ e compatibilização dos projetos $(58,33 \%)$. Também destacamos as questões que foram avaliadas positivamente pelos engenheiros de obra: interesse da incorporadora/ construtora em adotar novas práticas e ferramentas para o planejamento e controle do processo de projeto $(95,65 \%)$ e disponibilização de informações do processo de projeto $(54,17 \%)$.

Percebe-se divergência entre projetistas e construtores na avaliação quanto à compatibilização dos projetos e as soluções de projeto adotadas na perspectiva da execução da obra. Em ambos os casos, as respostas de projetistas mostraram satisfação, enquanto os engenheiros expressaram insatisfação.

No questionário, havia uma pergunta aberta quanto às práticas utilizadas no planejamento e controle do processo de projeto pelos projetistas (questão 11). O resultado pode ser verificado no gráfico 1. A mesma questão foi aplicada para os construtores (gráfico 2), sendo as três práticas mais citadas: planejamento de longo prazo $(25.00 \%)$, planejamento de médio prazo (20.83\%) e planejamento de curto prazo 
(19.44\%), ou seja, o last planner é fortemente aplicado. Para os projetistas, o planejamento de curto prazo tem sido mais recorrente.

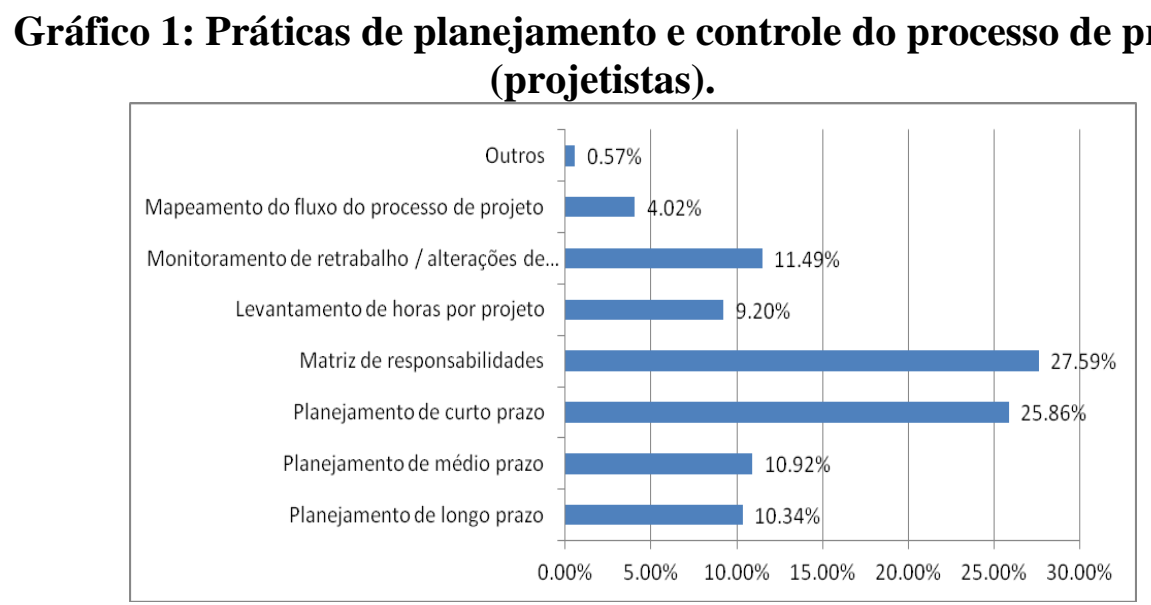

Fonte: os autores.

\section{Gráfico 2: Práticas de planejamento e controle do processo de projeto usado em} construtoras.

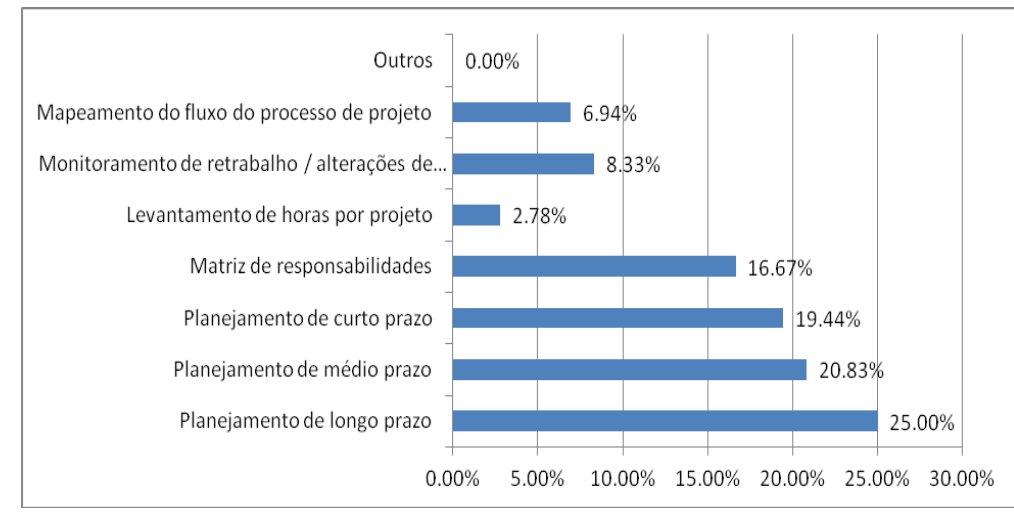

Fonte: os autores.

Havia uma questão a respeito dos softwares utilizados, com os seguintes resultados: $64,58 \%$ dos projetistas relataram o uso de CAD, enquanto $35,42 \%$ o uso de BIM; $86,67 \%$ dos construtores usam CAD e 70,59\% utilizam o MS Project. Todos os escritórios de projeto de cálculo estrutural utilizam software BIM. Uma questão a ser observada é que o uso do BIM é limitado para parte dos escritórios de arquitetura e os escritórios de cálculo estrutural, não sendo adotado por projetistas de instalações.

Foi aplicada entre os projetistas uma questão fechada com múltiplas respostas sobre o conhecimento ou familiaridade com os seguintes termos encontrados na literatura: construção enxuta/ lean construction (41,51\%); gerenciamento de projetos $(38,36 \%)$; lean design (5,66\%); PMI e Engenharia Simultânea (5,03\%, cada); PMBOK (4,40\%) e IGLC $(1,89 \%)$. Esta questão também foi respondida entre os construtores: construção enxuta/ lean construction (47,47\%); gerenciamento de projetos (24,24\%); PMI $(11,11 \%)$; PMBOK (10,10\%); IGLC (5,05\%); lean design $(2,02 \%)$; e Engenharia Simultânea $(0,00 \%)$. Esta questão tinha como objetivo compreender o nível de familiaridade de projetistas e construtores com as atuais teorias que tratam do processo de projeto e construção.

Também foram questionadas as razões pelas quais os projetistas e construtores estão interessados na adoção de novas práticas e ferramentas para o planejamento e controle do processo de projeto (Gráfico 3 e 4). Foi verificado semelhanças nos dois grupos: há 
um aumento na qualidade dos projetos e redução de prazos. Porém, a principal razão apontada pelos construtores foi a redução de custos $(28,13 \%)$.

\section{Gráfico 3: Razões para adotar novas práticas e ferramentas para o planejamento e controle do processo de projeto (projetistas).}

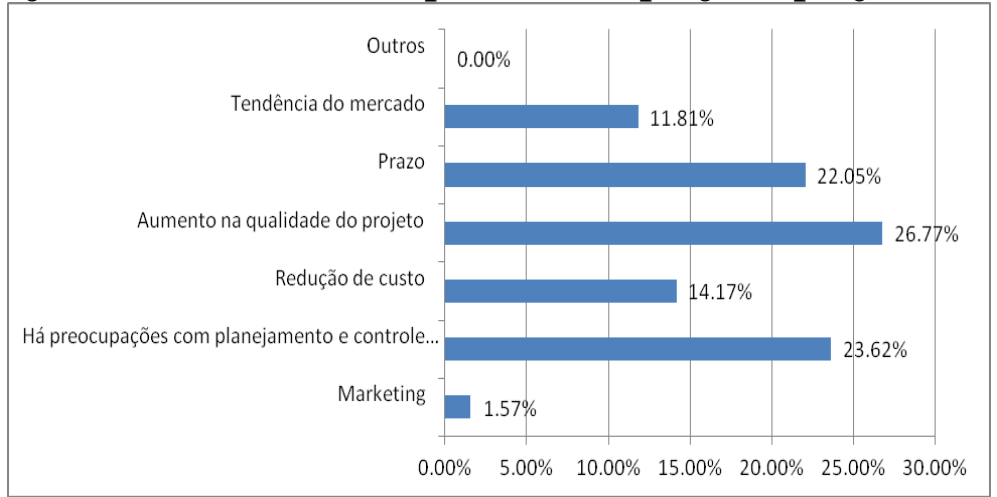

Fonte: os autores.

\section{Gráfico 4: Razões para adotar novas práticas e ferramentas para o} planejamento e controle do processo de projeto por construtores.

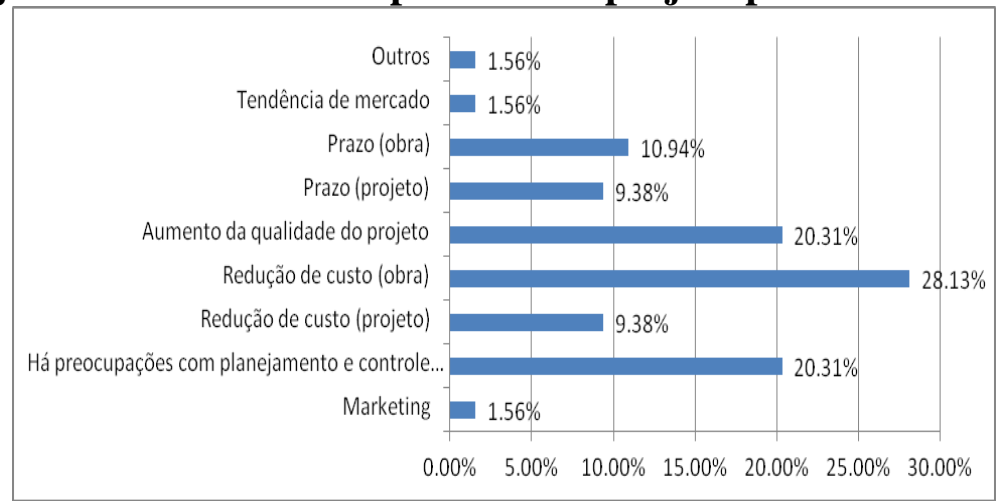

Fonte: os autores

Outra questão aberta aplicada, para ambos os grupos, foi sobre os pontos positivos e negativos da metodologia de planejamento do processo de projeto (pergunta 9). Os resultados estão detalhados no quadro 1 .

Quadro 1: Avaliação da metodologia de planejamento do processo de projeto

\begin{tabular}{|c|c|c|}
\hline & Projetistas & Construtores \\
\hline \multirow{6}{*}{ Positivo } & $\begin{array}{l}\text { Relação de parceria entre a equipe, e } \\
\text { abertura para novas soluções }(25 \%) \text {; }\end{array}$ & $\begin{array}{l}\text { Planejamento dos processos de projeto } \\
\text { e construção }(26.67 \%) \text {; }\end{array}$ \\
\hline & \multirow{2}{*}{$\begin{array}{l}\text { Transmissão de Know-how } \\
\text { construtivo; valorização do detalhe do } \\
\text { projeto }(25 \%) ;\end{array}$} & Análise crítica dos projetos (20\%); \\
\hline & & $\begin{array}{l}\text { Existe um departamento de } \\
\text { gerenciamento de projetos }(13.33 \%) ;\end{array}$ \\
\hline & \multirow{2}{*}{$\begin{array}{l}\text { Organização de dados e informações } \\
\text { sobre o projeto em plataformas on-line } \\
\text { de gerenciamento }(18.75 \%)\end{array}$} & A integração da equipe $(13.33 \%)$ \\
\hline & & Uso de novas tecnologias (13.33\%) \\
\hline & $\begin{array}{l}\text { Pesquisa de mercado, frequência de } \\
\text { demanda de projetos, pró-atividade } \\
\text { para resolver problemas e questões } \\
\text { pendentes }(18.75 \%) \text {. }\end{array}$ & $\begin{array}{l}\text { Projetistas parceiros, customização } \\
(13.34 \%) \text {. }\end{array}$ \\
\hline \multirow{2}{*}{ Negativo } & Retrabalho $(29.17 \%)$ & O prazo de entrega $(37.5 \%)$ \\
\hline & Planejamento dos processos & O planejamento do projeto $(31.25 \%)$; \\
\hline
\end{tabular}




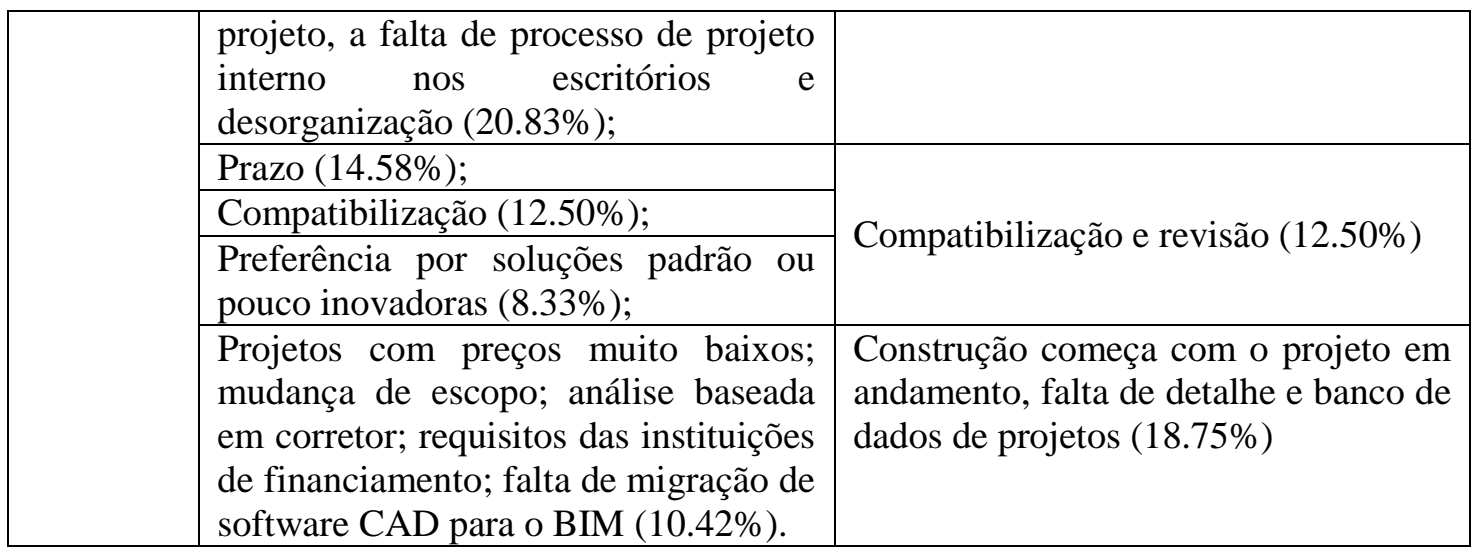

Fonte: os autores

Um ponto negativo citado pelos projetistas foi a preferência por soluções padrão ou pouco inovadoras, mas os construtores afirmam a busca de novas tecnologias como um ponto positivo. Isso demonstra uma tendência aos construtores voltar sua atenção às questões construtivas, enquanto questões de geração de valor, que são especificadas no projeto, poderiam ser melhoradas, na visão dos projetistas.

Entre as dificuldades encontradas no processo de projeto nos escritórios de projeto (gráfico 5) os mais citados foram: retrabalho em excesso $(39,86 \%)$ e cumprimento de prazos $(26,81 \%)$. A mesma questão (gráfico 6), quando aplicada às empresas de incorporação e construção, obteve como principais itens o cumprimento de prazo (35\%) e compatibilização (33\%).

Apesar de as novas visões do processo de projeto (conversão, fluxo e valor) serem conhecidas há algum tempo e o fato de que as empresas de construção adotam princípios da construção enxuta, percebe-se que o processo de projeto requer melhorias quanto à integração, o fluxo de informação e geração de valor. Assim, cita-se como oportunidades de melhoria detectada neste trabalho a gestão do fluxo e aplicação do last planner para projeto a partir do mapeamento das restrições do processo de projeto.

\section{Gráfico 5: visão das dificuldades do Gráfico 6: visão dificuldades do processo} processo de projeto em escritórios de projeto na construção. de projeto.
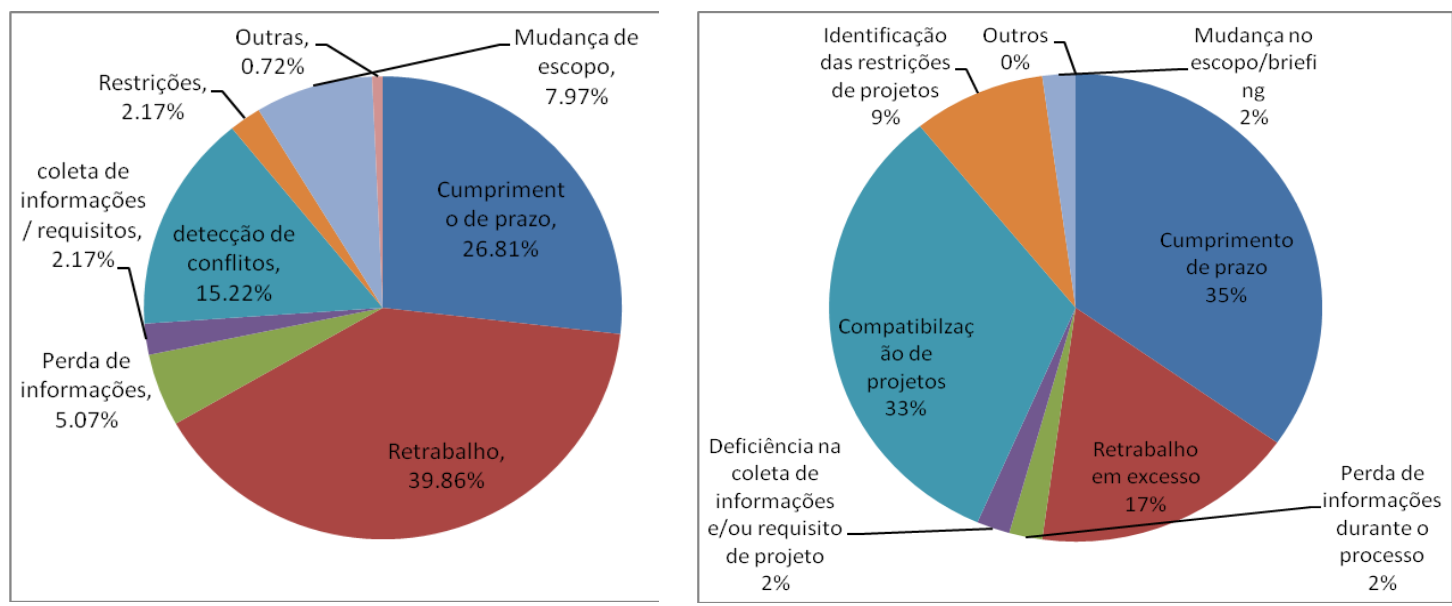

Fonte: os autores. 


\section{CONCLUSÕES}

Os dados apresentados na seção anterior mostraram que o processo de projeto nessas empresas ainda é tradicional. Como consequência desta abordagem tradicional, temos falhas na elaboração do projeto, no desenvolvimento do produto e na execução da obra, gerando perdas, além de possíveis desvios na geração de valor sob o ponto de vista do cliente (usuário final). O modelo tradicional de PDP utiliza uma abordagem com interações negativas que resultam em diversos retrabalhos devido à tomada de decisões prematuras, gerando as necessidades de compatibilização apontadas nos questionários. Em consequência, consome-se tempo e recursos os quais constituem em desperdícios. Apesar de o planejamento do processo de projeto ter sido citado como um dos principais fatores negativos, poucas empresas construtoras demonstraram possuir uma equipe ou departamento dedicado para esta função.

Algumas divergências entre projetistas e construtores, tais como, quanto à compatibilização dos projetos e as soluções de projeto adotadas na perspectiva da execução da obra denotam falha de comunicação no feedback entre execução e projeto e a existência de interações negativas em excesso. Portanto, ausência de processos de melhoria contínua no desenvolvimento de produtos imobiliários e de um sistema enxuto de desenvolvimento de produtos.

A presente pesquisa permitiu a avaliação do nível de satisfação de projetistas e construtores em relação ao processo de desenvolvimento de projetos do setor imobiliário residencial em Fortaleza/ Ce. Entre os principais resultados obtidos no presente trabalho pode-se destacar o diagnóstico do processo de desenvolvimento de produto imobiliário. Ressalta-se que a amostra é representativa tanto dos escritórios de projeto como de construtoras que atuam neste mercado.

Oportunidades de melhoria e prioridades de intervenção foram identificadas a partir da análise descritiva das questões. Os principais problemas de insatisfação identificados a partir da perspectiva de projetistas e construtores foram: retrabalho; planejamento dos processos de projeto; os prazos; e compatibilização.

\section{AGRADECIMENTOS}

Nós gostaríamos de agradecer à Universidade Federal do Ceará, CAPES e FUNCAP por apoiar esta pesquisa.

\section{REFERÊNCIAS}

Andersen, Janthea et al. (2005). "Design management in a construction company". In: ASEE/AaeE 4th Global Colloquium on Engineering Education. The School of Engineering, The University of Queensland, 2005. p. 1-10.

Ballard, Glenn; Koskela, Lauri. (1998). "On the agenda of design management research". In: Proceedings of the 6th annual conference of the International Group for Lean Construction.

Fabrício, Márcio Minto. (2002). "Projeto simultâneo na construção de edifícios”. 2002. $350 \mathrm{f}$. Tese (Doutorado) - USP, São Paulo.

Jørgensen, Bo. (2006). "Integrating lean design and lean construction: processes and methods". Doctoral dissertation. The Technical University of Denmark.

Koskela, L. (2000). "An exploration towards a production theory and its application to construction". PhD Dissertation, VTT Building Technology, Espoo, Finland. 296 pp., VTT Publications: 408, ISBN 951-38-5565-1; 951-38-5566-X. (available at http://www.leanconstruction.org)

Morgan, J.; Liker, J. K. Sistema Toyota de desenvolvimento de produto: integrando pessoas, processo e tecnologia. Trad. Raul Rubenich. Porto Alegre: Bookman, 2008. 
Moura, Patricia Moreira. (2005). "Um estudo sobre a coordenação do processo de projeto em empreendimentos complexos". Dissertação de Mestrado - Programa de Pós-Graduação em Engenharia Civil, UFRGS, Porto Alegre.

Oliveira, O. J. (2004). "Gestão do processo de projeto na construção de edifícios". Integração (São Paulo), São Paulo, v. 38, p. 201-217.

Orihuela, P., Orihuela, J., Ulloa, K. (2011). "Tools for design management in building projects". IGLC 19, 10 pp. Lima, Peru.

Romano, Fabiane Vieira. (2003) "Modelo de referência para o gerenciamento do processo de projeto integrado de edificações". Florianópolis. 326p. Tese (Doutorado em Engenharia de Produção) - Programa de Pós-Graduação em Engenharia de Produção, Universidade Federal de Santa Catarina.

Trescastro, M.G. (2005) "Diretrizes para a segmentação e sequenciamento das atividades no processo de projeto em ambientes simultâneos na construção civil”. Dissertação de Mestrado (Mestrado em Engenharia Civil) - Núcleo Orientado para a Inovação da Edificação, Programa de Pós-Graduação em Engenharia Civil, Universidade Federal do Rio Grande do Sul, Porto Alegre.

Tzortzopoulos, P., Formoso, C. (1999) "Considerations on Application of Lean Construction to Design Management". In: Proceedings for the 7th Annual Conference of the International Group for Lean Construction (IGLC-7). Berkeley, California, pp. 335-344. 